\title{
End-stage care of persons with alzheimer's disease
}

\begin{abstract}
Alzheimer's disease is a devastating neurodegerative disorder that irreversibly affects our cognitive functions, especially memory. This review will give an overview of clinical issues associated with the end-of-life care of AD. By the time end-stage AD is present, the ability to communicate their pain and discomfort with caregivers as well as having significant ability to perform ADL have significantly decreased. These changes are frequently accompanied by neuropsychiatric symptoms that further complicate the patient's EOL care. Delirium is additionally a common clinical challenge among the patients in this stage. When the patients start becoming indifferent towards eating, refusing food or experiencing impaired swallowing, their caregiver involvement plays a substantial role in decision-making. In the process of all these changes, caregivers often experience the burden of emotional, physical, and financial stressors. The authors address the importance of healthcare systems and clinicians making efforts to ameliorate the sufferings of the patients with end-stage $\mathrm{AD}$ and their caregivers.
\end{abstract}

Volume I Issue I - 2017

\author{
Ralph R Mckenzie,' Kye Y Kim ${ }^{2,3}$ \\ 'Carilion Clinic Virginia Tech Carilion School of Medicine \\ Psychiatry Residency Program, USA \\ ${ }^{2}$ Department of Psychiatry and Behavioral Medicine,Virginia \\ Tech Carilion School of Medicine, USA \\ ${ }^{3}$ Carilion Center for Healthy Aging, USA
}

Correspondence: Kye Y Kim, MD, Carilion Center for Healthy Aging, 200I Crystal Spring Avenue, \#302, Roanoke, VA, USA 240I4, Tel (540) 98I-7653, Fax (540) 98I-7469,

Email kykim@carilionclinic.org

Received: March 29, 2017| Published: May 02, 2017

Keywords: alzheimer's disease, end-of-life care, pain, neuropsychiatric symptoms, delirium, food refusal, end-stage decisions, emotional support

Abbreviations: $\mathrm{AD}$, alzheimer's disease; EOL, end-of-life; ADL, activities of daily living; $\mathrm{NH}$, nursing homes

\section{Introduction}

With the impending influx of the baby boomers into the existing geriatric cohort with chronic disabling conditions, end-of-life (EOL) care has increasingly become a significant component of the health care system. Additionally, the expected rise in survival among Americans is secondary to environmental and social factors, as well as improvements in life saving technologies. ${ }^{1}$ While EOL care has been a relatively common option for terminal cancer patients, the utilization of EOL care in Alzheimer's disease (AD) and other dementias has only become available more recently. The National Hospice and Palliative Care Organization (NHPCO) reports that approximately 9.8 percent of the nation's hospice census of 2005 was comprised of patients with dementia. ${ }^{2}$ Although current Medicare regulations require that patients have a prognosis of less than six months of life in order to be eligible for hospice benefits, they can still get hospice care if their physician recertifies that the patient is terminally ill. In this article, the author will explore situations unique to patients with end-stage AD and their caregivers that can contribute to improved care strategies.

\section{General features}

Alzheimer's disease (AD) is the most common cause of dementing disorders among persons over age 65 , with expectations of individuals diagnosed with AD impacting an estimated 13.8 million by $2050 .{ }^{3} \mathrm{In}$ fact, new diagnosis of AD will be made every 33 seconds by 2050 . Initially presenting with difficulty in solidifying new memories, ${ }^{4}$ $\mathrm{AD}$ is "officially listed as the sixth-leading cause of death in the United States". Whereas the course of AD is predictable, the rate of disease progression is not. Marked by gradual decline, with significant morbidity during end stage, ${ }^{6}$ survival time, on average, following diagnosis of $\mathrm{AD}$ is between 4-8 years. ${ }^{7}$ A prospective study demonstrated that comorbid conditions, such as diabetes, congestive heart failure, and ischemic heart disease were associated with reduced survival of these patients. ${ }^{8}$ The end stage of AD is marked by loss of independent functioning. ${ }^{9}$ In addition, the patient often is unable to communicate with loved ones, as well as having significant impairment in ability to perform activities of daily life (ADL). ${ }^{10}$ Importantly, difficulties in swallowing, immobility, and malnutrition are particular challenges to the population, which advances risk for life ending conditions, most notably, pneumonia. ${ }^{11}$

\section{Pain}

An estimated $50-93 \%$ of patients with AD experience pain, ${ }^{12}$ with resulting associated emotional distress impacting quality of life. ${ }^{13}$ In fact, contributions from associated comorbidities, including pressure ulcers, falls, osteoarthritis, and neuropathy often impact the $\mathrm{AD}$ population. ${ }^{14}$ Complicated by impaired communication, patients with severe $\mathrm{AD}$ have difficulty with self-reporting pain, leading to reduced detection and delayed management. ${ }^{15}$ Interestingly, observational pain assessments utilize six domains of behavioral interpretation of pain, highlighted by American Geriatric Society, specifically body language, alterations in mental status, activity variation, facial expression, interactions with others, and negative vocalization. ${ }^{16}$ Similarly, painful indicators can include grimacing, moaning, wandering, agitation, inappropriate speech, aggression, restlessness are often useful. ${ }^{17}$ Lastly, the Pain Assessment in Advanced Dementia (PAINAD) and Pain Assessment for the Dementing Elder (PADE) are tools developed specifically for patients with $\mathrm{AD}$, but they need further research for reliability and validity. ${ }^{18,19}$ The most common intervention in pain management is to use a variety of analgesic agents. ${ }^{20}$ The transdermal fentanyl patch may be helpful to patients who are unable to swallow pills. But because of the drug's extreme potency and the potential for over dosage, this patch should not be used in "opiate-naïve" elderly patients or in those unaccustomed to the respiratory depression caused by opiates..$^{21} \mathrm{~A}$ non-narcotic agent, tramadol, may be useful to patients with end-stage $\mathrm{AD}$, which has potency similar to that of codeine but rarely causes respiratory depression. ${ }^{22}$

\section{Neuropsychiatric symptoms}

An estimated $80-90 \%$ of patients with AD experience neuropsychiatric symptoms during illness course. ${ }^{23}$ Behavioral manifestations of end stage $\mathrm{AD}$ are characterized by verbal and physical agitation, perceptual disturbances, and dis-inhibition. ${ }^{23}$ Such 
manifestations are associated with institutionalization, emotional distress, and mortality. ${ }^{24}$ In presence of agitation, it is critical to investigate additional potential causes of agitation, including underlying medical disorders, side effects of medications, hunger, fecal impaction or pain and searching for bedsores. ${ }^{25}$ Providers should continue with current psychotropic agents until patients are unable to swallow the pills. ${ }^{25}$ Antipsychotic drugs are the mainstay of treatment for psychotic symptoms and aggression and highpotency agents such as haloperidol are effective in controlling these behavioral symptoms. Second-generation antipsychotic agents such as risperidone, quetiapine, olanzapine and ziprasidone have an improved side-effect profile compared to its predecessors. ${ }^{26}$ Selective serotonin reuptake inhibitors are preferred agents with a favorable side-effect profile. ${ }^{27}$ Further attention should be given on expanding role of non-pharmacologic interventions of neuropsychiatric symptoms, specifically limiting environmental stimuli, behavioral strategies, and providing caregiver education. ${ }^{28}$

\section{Delirium}

The presence of cognitive impairment in end stage $\mathrm{AD}$ is a serious risk factor for the development of delirium. ${ }^{29}$ Importantly, delirium can feature behavioral manifestations, such as aggression, hallucinations, delusions, anxiety, and reversed sleep cycle. ${ }^{29}$ These behavioral disturbances can be overwhelming to the patient themselves and caregivers. ${ }^{29}$ However, lack of these manifestations can aid to mask presence of delirium. ${ }^{30}$ Critical to approach of delirious patients is to provide comfort and ensure safety through use of various nonpharmacologic and pharmacologic interventions. ${ }^{31}$ Behavioral symptoms of delirious patients with end-stage $\mathrm{AD}$ generally respond well to antipsychotic agents regardless of causes of delirium. ${ }^{31}$

\section{Food refusal}

Maintaining adequate nutritional status in patients with end stage $\mathrm{AD}$ represents a significant challenge, with dysphagia contributions from presence of apraxia and cognitive decline. ${ }^{32}$ Patients will often be indifferent towards eating, refuse food, and may have impaired swallowing. ${ }^{33}$ As a result, caregiver involvement plays a substantial role in supporting feeding habits. ${ }^{34}$ Furthermore, choking may be prevented by avoidance of thin liquids, providing boluses of food with sufficient moisture, and keeping patients in a seated position. ${ }^{35}$ Enteral tube feeding is inevitable when patients with end-stage AD stop eating or experience significant difficulty in swallowing. ${ }^{36}$

\section{Settings of EOL care}

Over the past century, the site of death for AD patients has shifted to nursing homes (NH) and homes. ${ }^{37}$ In fact, "nearly $70 \%$ of persons with advanced dementia die" under NH care. ${ }^{38}$ Unfortunately, nursing homes have difficulty managing palliative care needs of end stage AD. Notably, assessment and management of pain are frequent concerns ${ }^{39}$ Furthermore, in an extensive survey of family members of 1578 decedents, ${ }^{40}$ Teno and her colleagues concluded that many people dying in $\mathrm{NH}$ or hospitals have unmet needs for symptom amelioration, physician communication, emotional support, and respectful attention. Also, family members of decedents who received care at home with hospice services had fewer concerns with the amount of emotional support provided to the patients. ${ }^{40}$

\section{Caregiver end-stage decisions}

Prior to onset of dementia, patient would ideally have prepared an advance directive, living will and appointed Durable Power of Attorney. ${ }^{41}$ When unavailable, providers should discuss relevant EOL issues with caregivers, including cardio-pulmonary resuscitation (CPR), hospitalization, artificial feeding and use of antibiotics for recurrent infections..$^{42}$ It is often useful to address treatment concerns in terms of the potential outcomes of various options, goals of medical care, and associated risks. Providers need to ensure clear and direct guidance to caregivers, while assuring consideration and respect for treatment values. ${ }^{43}$ Lastly, it is important to assure caregivers that their loved ones will receive supportive measures, even if they decide not to opt for acute medical interventions. ${ }^{43}$

\section{Emotional support}

Caregivers often experience the burden of emotional, physical, and financial stressors associated with end stage AD. ${ }^{44}$ Likely secondary to duration of care, associated behavioral symptoms, and decline during illness course, ${ }^{44}$ caregivers frequently experience depressive symptoms. ${ }^{45}$ Insufficient attention has been given to the impact of EOL care on caregivers or to their responses to the death of the patient. For instance, care strain is a significant factor in advancing mortality risk of associated caregiver. ${ }^{46}$ Psychiatrists are uniquely positioned to assist caregivers with their emotional needs associated with EOL care of AD patients. ${ }^{47}$ The local Alzheimer's Association and the National Hospice and Palliative Care Organization also provide such support. The guidelines recently developed by the National Consensus Project for Quality Palliative Care offer a comprehensive format to improve the quality of care, efficiency of care delivery, and patient/caregiver satisfaction in psychological and psychiatric aspects of care. ${ }^{48}$

\section{Conclusion}

EOL care for individuals with end-stage AD is increasingly important because of the rising number of AD patients. However, barriers exist to the provision of high-quality EOL care for these patients. Future consideration of developing clinical practice guidelines specific to the EOL care of such individuals and their caregivers would assist practitioners in further enhancing their care of individuals with end-stage AD. Regardless of the last place of their care, healthcare systems and clinicians should make efforts to ameliorate the sufferings of the patients with end-stage of $\mathrm{AD}$ and their caregivers.

\section{Acknowledgements}

None.

\section{Conflict of interest}

The author declares no conflict of interest.

\section{References}

1. Ortman JM, Velkoff VA, Hogan H. An Aging Nation: The older population in the United States. Current Population Reports. US Census Bureau, Washington, USA: Springer; 2014. p. 25-1140.

2. National Hospice and Palliative Organization. Facts and Figures on Hospice Care. 2015. p. 1-17.

3. Herbert LE, Weuve J, Scherr PA, et al. Alzheimer disease in the United States (2010-2050) estimated using the 2010 Census. Neurology. 2013;80(19):1778-1783.

4. Alzheimer's Association. Alzheimer's disease facts and figures. Alzheimer's \& Dementia. 2016;12(4):459-509.

5. Murphy SL, Kochanek KD, Xu J, et al. National center for health statistics. Deaths: final data for 2012. Natl Vital Stat Rep. 2014;63(9):1117. 
6. Arrighi HM, Neumann PJ, Lieberburg IM, et al. Lethality of Alzheimer disease and its impact on nursing home placement. Alzheimer Dis Assoc Disord. 2010;24(1):90-95.

7. Ganguli M, Dodge HH, Shen C, et al. Alzheimer disease and mortality: A 15-year epidemiological study. Archives of Neurology. 2005;62(5):779784

8. Larson EB, Shadlen MF, Wang L, et al. Survival after initial diagnosis of Alzheimer's disease. Annuals of Internal Medicine. 2004;140(7):501509

9. Wilson RS, Segawa E, Boyle PA, et al. The natural history of cognitive decline in Alzheimer's disease. Psychol Aging. 2012;27(4):1008-1017.

10. Ornstein K, Gaugler JE. The problem with "problem behaviors": A systematic review of the association between individual patient behavioral and psychological symptoms and caregiver depression and burden within the dementia patient-caregiver dyad. Int Psychogeriatr. 2012;24(10):1536-1552.

11. Brunnstrom HR, Englund EM. Cause of death in patients with dementia disorders. Eur J Neurol. 2009;16(4):488-492.

12. Corbett A, Husebo BS, Achterberg WP, et al. The importance of pain management in older people with dementia. $\mathrm{Br}$ Med Bull. 2014;111(1):139-148

13. Corbett A, Husebo B, Malcangio M, et al. Assessment and treatment of pain in people with dementia. Nat Rev Neurol. 2012;8(5):264-274.

14. Stubbs B, Thompson T, Solmi M, et al. Is pain sensitivity altered in people with Alzheimer's disease? A systematic review and meta-analysis of experimental pain research. Exp Gerontol. 2016;82:30-38.

15. Lichtner V, Downding D, Esterhuizen $P$, et al. Pain assessment for people with dementia: a systematic review of systematic reviews of pain assessment tools. BMC Geriatrics. 2014;14:138.

16. AGS panel on persistent pain in older persons. The management of persistent pain in older persons. J Am Geriatr Soc. 2012;50(suppl 6):S205-224.

17. Burfield AH, Wan TT, Sole ML, et al. Behavioral cues to expand a pain model of the cognitively impaired elderly in long-term care. Clin Interv Aging. 2012;7:207-223.

18. Warden V, Hurley AC, Volicer L. Development and psychometric evaluation of the pain assessment in advanced dementia (PAINAD) scale. J Am Med Dir Assoc. 2003;4(1):9-15.

19. Villanueva MR, Smith TL, Erickson JS, et al. Pain assessment for the dementing elderly (PADE): Reliability and validity of a new measure. $J$ Am Med Dir Assoc. 2003;4(1):1-8.

20. Achterberg WP, Pieper M, Van Dalen Kok AH, et al. Pain management in patients with dementia. Clin Interv Aging. 2013;8:1471-1482.

21. McLachlan AJ, Bath S, Naganathan V, et al. Clinical pharmacology of analgesic medicines in older people: impact of frailty and cognitive impairment. Br J Clin Pharmacol. 2011;71(3):351-364.

22. Rodger K, Greasley Adams C, Hodge Z, et al. Expert opinion on the management of pain in hospitalized older patients with cognitive impairment: a mixed methods analysis of a national survey. $B M C$ Geriatr. 2015;15:56

23. Nowrangi MA, Lyketsos CG, Rosenburg PB. Principles and management of neuropsychiatric symptoms in Alzheimer's dementia. Alzheimer's Research \& Therapy. 2015;7:12.

24. Tatsumi H, Nakaaki S, Torii K, et al. Neuropsychiatric symptoms predict change in quality of life of Alzheimer disease patients: a two-year followup study. Psychiatry and Clinical Neurosciences. 2009;63:374-384.
25. Sampson EL. Palliative care for people with dementia. Br Med Bull. 2010;96(1):159-174.

26. Lopez OL, Becker JT, Chang YF, et al. The long-term effects of conventional and atypical antipsychotics in patients with probable Alzheimer's disease. Am J Psychiatry. 2013;170(9):1051-1080.

27. Sepehry AA, Lee PE, Hsiung GY, et al. Effect of selective serotonin reuptake inhibitors in Alzheimer's disease with comorbid depression: a meta-analysis of depression and cognitive outcomes. Drugs Aging. 2012;29(10):793-806.

28. Olazaran J, Reisberg B, Clare L, et al. Nonpharmacological therapies in Alzheimer's disease: a systematic review of efficacy. Dement Geriatr Cogn Disord. 2010;30(2):161-178.

29. Cerejeira J, Mukaetova Ladinska EB. A clinical update on delirium: From early recognition to effective management. Nursing Research and Practice. 2011;1-12.

30. Yang FM, Marcantonio ER, Inouye SK, et al. "Phenomenological subtypes of delirium in older persons: patterns, prevalence, and prognosis". Psychosomatics. 2009;50(3):248-254.

31. National institute for health and clinical excellence. Clinical guidelines103-Delirium. NICE. 2010. p. 1-49.

32. Cipriani G, Carlesi C, Lucetti C, et al. Eating behaviors and dietary changes in patients with dementia. Am J Alzheimers Dis Other Demen. 2016;31(8):706-716.

33. Correia SM, Morillo LS, Filho JW, Swallowing in moderate and severe phases of Alzheimer's disease. Arq Neuropsiquiatr. 2010;68(6):855-861.

34. Wu HS. Predictors of hyperphagia in institutionalized patients with dementia. J Nurs Res. 2014;22(4):250-258.

35. Chen LL, Li H, Lin R, et al. Effects of a feeding intervention in patients with Alzheimer's disease and dysphagia. J Clin Nurs. 2015;25(5-6):699707.

36. Goldberg LS, Altman KW. The role of gastrostomy tube placement in advanced dementia with dysphagia: a critical review. Clin Interv Aging 2014;9:1733-1739.

37. Teno JM, Gozalo PL, Bynum JP, et al. Change in end-of-life care for medicare beneficiaries: site of death, place of care, and health care transitions in 2000, 2005, and 2009. JAMA. 2013;309(5):470-477.

38. Ersek M, Carpenter JG. Geriatric palliative care in long-term care settings with a focus on nursing homes. J Palliat Med. 2013;16(10):1180-1187.

39. Miller SC, Lima JC, Looze J, et al. Dying in U.S. nursing homes with advanced dementia: How does health care use differ for residents with, versus without, end-of-life Medicare skilled nursing facility care. $J$ Palliat Med. 2012;15(1):43-50.

40. Teno JM, Clarridge BR, Casey V, et al. Family perspectives on end-oflife care at the last place of care. JAMA. 2004;291(1):88-93.

41. Muramoto O. Socially and temporally extended end-of-life decisionmaking process for dementia patients. Journal of Medical Ethics. 2011;37(6):339-343

42. Hickman S, Nelson C, Perrin N, et al. A Comparision of Methods to Communicate Treatment Preferences in Nursing Facilities: Traditional Practices versus the Physician Orders for Life-Sustaining Treatment (POLST) Program. J Am Geriatr Soc. 2011;58(7):1241-1248.

43. Arcand M. End-of-life issues in advanced dementia. Can Fam Physician. $2015 ; 61(4): 330-334$

44. Kasper JD, Freedman VA, Spillman BC. Disability and Care Needs of Older Americans by Dementia Status: An Analysis of the 2011 National Health and Aging Trends Study. US Department of Health and Human Services; 2011. 
45. Zhu CW, Scarmeas N, Ornstein K, et al. Health-care use and cost in dementia caregivers: Longitudinal results from the Predictors Caregiver Study. Alzheimers Dementia. 2015;11(4):444-454.

46. Perkins M, Howard VJ, Wadley VG, et al. Caregiving strain and all-cause mortality: Evidence from the REGARDS Study. J Gerontol B Psychol Sci Soc Sci. 2013;68(4):504-512.
47. Noel MA, Kaluzynski TS, Templeton VH. Quality dementia care: Integrating caregivers into a chronic disease management model. $J \mathrm{Appl}$ Gerontol. 2015;36(2):195-212.

48. Vedel I, Ghadi V, Lapointe L, et al. Patients', family caregivers', and professionals' perspectives on quality of palliative care: A qualitative study. Palliat Med. 2014;28(9):1128-1138. 